\title{
A redemocratização de 1945 no Paraná e as eleições de 1945 e
} 1947

\section{The democratization in Paraná in 1945 and the 1945 and 1947 elections}

\section{Alessandro Batistella*}

\begin{abstract}
Resumo
O presente artigo visa, em um primeiro momento, a analisar o processo de redemocratização de 1945 no Paraná, sobretudo a gênese e os anos iniciais dos principais partidos políticos no estado. Em um segundo momento, o foco de análise será nos posicionamentos dos principais partidos políticos diante das eleições de 1945 e 1947 no Paraná.
\end{abstract}

Palavras chaves: redemocratização de 1945; Paraná; partidos políticos; eleições de 1945; eleições de 1947.

\begin{abstract}
First of all, this article aims to analyze the democratization process in Paraná in 1945, particularly the genesis of the main State political parties early years. In a second step, the analysis will focus on the main political parties positions before the 1945 and 1947 elections in Paraná.
\end{abstract}

Key-words: 1945 re-democracy; Paraná political parties; 1945 elections; 1947 elections.

\section{Considerações Iniciais}

A partir de 1942, com o Estado Novo dando seus primeiros sinais de fissura $^{1}$, as vozes que clamavam pelo retorno do país ao regime democrático

\footnotetext{
* Doutor em História pela Universidade Federal do Rio Grande do Sul (UFRGS). Professor do curso de História da Universidade de Passo Fundo (UPF).E-mail: alessandrobatistella@yahoo.com.br

${ }^{1}$ Segundo José Murilo de Carvalho, a entrada do Brasil na Segunda Guerra Mundial ao lado dos americanos semeou a crise do Estado Novo, pois dentro do governo havia duas alas: uma simpatizante aos americanos (representado pelo agora embaixador do Brasil em Washington Osvaldo Aranha) e outra simpatizante aos alemães, representada por elementos da cúpula militar, como Dutra e Góis Monteiro,
} 
passaram a ecoar cada vez mais alto, pois diversos setores da sociedade estudantes, intelectuais, empresários, comunistas, liberais, militares e até mesmo integrantes do governo - passaram a pressionar cada vez mais Getúlio Vargas pelo fim da ditadura estadonovista.

Com as relações com a cúpula militar desgastada e enfrentando pressões internas e externas ${ }^{2}$, o governo Vargas - embora contasse com o apoio de uma expressiva parcela da população brasileira, sobretudo dos trabalhadores urbanos - dava claros sinais de esgotamento. Em outubro de 1943, um grupo de políticos e intelectuais mineiros publicou o Manifesto dos Mineiros ${ }^{3}$, no qual conclamavam eleições e o retorno do país ao sistema democrático, simbolizando o início da oposição aberta contra o Estado Novo.

A partir de então, com as articulações da oposição e com a eclosão de manifestações mais veementes a favor do regime democrático, sucederam-se dois acontecimentos emblemáticos, sinalizando que o Estado Novo estava em seu epílogo: a) no final de 1944 é lançado o nome do Brigadeiro Eduardo Gomes como candidato à sucessão de Vargas e começou-se a especular o nome do general Eurico Gaspar Dutra como outro candidato à sucessão; b) em 22 de fevereiro de 1945, José Américo de Almeida, rompendo o cerco da censura, concedeu entrevista aos jornais exigindo eleições livres e exaltando a candidatura de Eduardo Gomes ${ }^{4}$.

A essa altura dos acontecimentos, o fim do Estado Novo e a volta do país ao regime democrático mostravam-se inevitáveis. Diante dessa situação, o governo Vargas buscou planejar e conduzir o processo de transição, denominado por Luiz Werneck Vianna ${ }^{5}$ como "redemocratização pelo alto",

além de Filinto Müller. Dessa forma, a opção pelo lado americano representou o início da cisão entre Vargas e os militares, que até então havia o apoiado e o sustentado no poder. Cf. CARVALHO, José Murilo de. Vargas e os militares: aprendiz de feiticeiro. In: D'ARAUJO, Maria Celina (Org.). As instituiçôes brasileiras da Era Vargas. Rio de Janeiro: EDUERJ/FGV, 1999, p. 55-82.

${ }^{2}$ A pressão externa pela redemocratização do Brasil aumentava com a derrocada dos países do Eixo e a iminente vitória dos países aliados, comprometidos com os valores da liberal democracia.

3 "O Manifesto dos Mineiros, reconhecidamente, marcou o início de uma fase na qual os protestos contra o regime de Vargas assumiram forma mais organizada, e a imprensa, menos tímida, difundia o pensamento de grupos civis e militares favoráveis à implantação de um governo liberal-democrático no país". In: SOUZA, Maria do Carmo Campello de. Evolução e crise do sistema partidário. In: FLEISCHER, David V. (Org.). Os partidos políticos no Brasil. Brasília: UnB, 1981, v. 1, p. 63.

${ }^{4}$ Segundo Jorge Ferreira, a entrevista sinalizou à sociedade que os censores do DIP se afastaram das redações dos jornais, além de evidenciar que a ditadura dava sinais definitivos de cansaço. Cf. FERREIRA, Jorge. A democratização de 1945 e o movimento queremista. In: FERREIRA, Jorge; DELGADO, Lucilia de Almeida Neves (Orgs.). O Brasil republicano: o tempo da experiência democrática (1945-1964). Rio de Janeiro: Civilização Brasileira, 2003, v. 3, p. 16.

${ }^{5}$ Cf. VIANNA, Luiz W. Liberalismo e sindicatos no Brasil. 3. ed. Rio de Janeiro: Paz e Terra, 1989. 
cujos objetivos do governo varguista eram claros: garantir a manutenção do poder na nova ordem institucional.

Durante o processo de "transição pelo alto", o governo adotou uma série de medidas estratégicas. Primeiramente, a 28 de fevereiro de 1945, decretou o Ato Adicional no 9, estabelecendo eleições diretas para a presidência da República e proporcionais para o Congresso Nacional; em seguida, no dia 18 de abril, decretou anistia geral a seus adversários políticos; posteriormente, a 28 de maio de 1945, o governo decretou a chamada Lei Agamenon (ministro da Justiça da época), no qual marcou as eleições para o dia 2 de dezembro e regulamentou o novo código eleitoral e os requisitos para a formação dos partidos políticos. A grande inovação da referida lei era a obrigatoriedade, pela primeira vez na história republicana, da formação de partidos de caráter nacional ${ }^{6}$.

Lucília de Almeida Neves Delgado 7 observa que a Lei Agamenon estabeleceu que os partidos deveriam cumprir três condições para se habilitar eleitoralmente: a) possuir registro em cinco ou mais estados da federação (atuação em âmbito nacional); b) possuir um referendo inicial de pelo menos 10 mil eleitores; c) possuir personalidade jurídica, de acordo com o Código Civil.

A seguir, analisar-se-á a redemocratização de 1945 e o processo de formação dos principais partidos políticos no Brasil e no Paraná.

\section{A redemocratização de 1945 e o processo de formação dos partidos políticos}

Segundo Gláucio Soares ${ }^{8}$, inicialmente apenas três partidos dispunham de uma estrutura organizacional em nível nacional: o Partido Comunista Brasileiro (PCB), o Partido Social Democrático (PSD) e a União Democrática Nacional (UDN). Esses dois últimos, embora inexistentes durante o Estado Novo, representavam, respectivamente, o situacionismo e a oposição e dispunham de bases sócio-econômicas e de um aparelho organizacional

\footnotetext{
${ }^{6}$ Antes de 1945 o único partido político de caráter nacional existente no país era o Partido Comunista Brasileiro (PCB). Fundado em 1922 e com um programa partidário-ideológico bem definido, o partido, apesar da sua situação de clandestinidade, "conseguir manter, mesmo durante a ditadura do Estado Novo, uma estrutura organizacional nacional ancorada nas capitais e principais cidades do país”. Cf. SOARES, Gláucio A. D. Formação dos partidos nacionais. In: FLEISCHER, David V. (Org.). Os partidos políticos no Brasil. Brasília: UnB, 1981, v. 1, p. 7.

${ }^{7}$ Cf. DELGADO, Lucilia de Almeida Neves. Partidos políticos e frentes parlamentares: projetos, desafios e conflitos na democracia. In: FERREIRA; DELGADO, op. cit., p. 134.
}

${ }^{8}$ SOARES, op. cit., p. 7-8. 
nos níveis municipal e estadual, faltando-lhes apenas um trabalho de articulação, em âmbito nacional, das estruturas estaduais e locais já montadas. Já os demais partidos teriam um grande desafio: organizar um partido nacional a partir de bases precárias.

Durante o período pluripartidário de 1945-1965, os três principais partidos políticos brasileiros - excluído o PCB, novamente posto na ilegalidade em 1947 - foram o PSD, a UDN e o Partido Trabalhista Brasileiro (PTB), que estavam se articulando antes mesmo da promulgação da Lei Agamenon e que são considerados "criaturas de Vargas", uma vez que gravitavam de maneiras distintas - em torno da figura do então ditador estadonovista. Portanto, Vargas é considerado o eixo divisor do sistema partidário que se inaugurava em 1945.

A UDN, oficialmente fundada em 7 de abril $^{9}$ de 1945, surgiu como uma grande frente liberal-democrática de oposição ao Estado Novo e a Getúlio Vargas. Inicialmente, a UDN aglutinava grupos políticos bastante heterogêneos - quando não antagônicos - unidos em torno da reconquista das liberdades democráticas e do combate a um inimigo comum - o ditador estadonovista.

Maria Victoria Benevides ${ }^{10}$ identificou cinco grupos principais que compunham a UDN na época de sua fundação:

1. Os grupos oligárquicos destronados em 1930: os oligarcas mineiros liderados por Arthur Bernardes; os oligarcas paulistas liderados por Júlio Prestes; o grupo de Otávio Mangabeira na Bahia; o grupo de José Augusto no Rio Grande do Norte; o grupo de Leandro Maciel em Pernambuco; os clãs estaduais, como os Konder em Santa Catarina, os Caiados em Goiás e os Correia da Costa em Mato Grosso.

2. Os ex-aliados de Getúlio, marginalizados depois de 1930 ou em 1937: os tenentes que se sentiram traídos, como Eduardo Gomes e Juraci Magalhães; os membros da Aliança Liberal, como os gaúchos chefiados por Borges de Medeiros e os mineiros Antonio Carlos e Virgílio de Melo Franco; os políticos marginalizados, como José Américo, Flores da Cunha e Lima Cavalcanti; os que integraram o governo no período constitucional, como Pedro Aleixo e Odilon Braga, e saíram em 1937.

3. Os ex-integrantes do Estado Novo: são os políticos que apoiaram o golpe e tiveram cargos públicos durante a ditadura, mas romperam com Getúlio

\footnotetext{
9 "A data de 7 de abril foi escolhida para rememorar o 7 de abril de 1831 (dia da abdicação de D. Pedro I), festejada data do liberalismo brasileiro". Cf. BENEVIDES, Maria Victoria. A União Democrática Nacional. In: FLEISCHER, David V. (Org.). Os partidos políticos no Brasil. Brasília: UnB, 1981b, v. 1, p. 95.

${ }^{10} \mathrm{Cf}$. BENEVIDES, Maria Victoria de Mesquita. A UDN e o udenismo: ambigüidades do liberalismo brasileiro (1945-1965). Rio de Janeiro: Paz e Terra, 1981a, p. 28-32.
} 
antes de 1945. Por exemplo: Osvaldo Aranha, Adhemar de Barros (exinterventor em São Paulo) e Argemiro de Figueiredo (ex-interventor na Paraíba), entre outros.

4. Os grupos liberais nos estados: no Rio Grande do Sul o grupo liderado por Raul Pilla; em Minas Gerais o grupo de signatários do Manifesto dos Mineiros; entre outros exemplos.

5. As esquerdas: os políticos e intelectuais de tendência socialista, que formariam a Esquerda Democrática; os comunistas dissidentes do PCB, como Astrogildo Pereira; e integrantes do movimento estudantil, de tendências socialistas, atuantes nas Faculdades de Direito de São Paulo, Minas Gerais, Rio de Janeiro e Pernambuco.

Além da oposição sistemática a Vargas, esse heterogêneo grupo apoiava a candidatura do Brigadeiro Eduardo Gomes à sucessão presidencial.

Para as oposições coligadas, tratava-se do candidato ideal: tinha um alto posto militar, uma legenda de herói e uma tradição de lutas democráticas aliada a um "nome limpo", em todos os sentidos. Dos idealistas revolucionários contra o regime "carcomido" da República Velha, Eduardo Gomes era, sem duvida, o primus inter pares: o combatente de 1922 e o sobrevivente dos " 18 do Forte" (mais tarde revelaria, discretamente, serem apenas dez), o organizador do Correio Aéreo Nacional e o articulador da defesa aérea do Atlântico na Segunda Guerra Mundial. Surgia, também, como o candidato perfeito para atrair as simpatias das classes médias que aplaudiam o ideal moralizante, encarnado na figura exemplar de virtudes cristãs e cívicas do antigo tenente. Eduardo Gomes era, enfim, aquele que reunia as condições indispensáveis para a primeira tentativa de "união nacional" contra o Estado Novo ${ }^{11}$.

No Paraná, em fevereiro de 1945 os grupos opositores a Vargas começaram a articular a Frente Única do Paraná ${ }^{12}$, que reunia, entre outros nomes, o major Plínio Alves Monteiro Tourinho ${ }^{13}$, Joaquim Pereira de Macedo $^{14}$ (que representavam o grupo dos ex-aliados de Getúlio

\footnotetext{
${ }^{11}$ BENEVIDES, op.ct., 1981b, p. 96.

${ }^{12}$ Cf. "O momento nacional". Gazeta do Povo, 25 fev. 1945, p. 3.

13 "O major Plínio Tourinho era paranaense, oficial engenheiro do Exército, professor de astronomia da Universidade do Paraná e ligado por parentesco a famílias tradicionais do estado (família Alves, por parte de mãe). Foi o líder da Revolução de 1930 no Paraná”. In: OLIVEIRA, Ricardo Costa. Notas sobre a política paranaense no período de 1930 a 1945. In: OLIVEIRA, Ricardo Costa (Org.). A construção do Paraná moderno: políticos e política no governo do Paraná de 1930 a 1980. Curitiba: SETI, 2004, p. 15.

${ }^{14}$ Joaquim Pereira de Macedo nasceu em Porto de Cima em 1858 e era coronel da Guarda Nacional, nomeado em 1893 por Floriano Peixoto. Tendo sido deputado no Congresso Constituinte Estadual de 1892, tornou-se novamente deputado estadual em 1900-1901, quando foi presidente do Congresso Estadual Camarista (1905-1908) e prefeito de Curitiba (1908-1912); foi ainda presidente da Aliança Liberal do Paraná e prefeito revolucionário de Curitiba (1930-1931). In: OLIVEIRA, op. cit., p. 21-25.
} 
marginalizados depois de 1930), Laerte Munhoz ${ }^{15}$, Arthur Ferreira dos Santos $^{16}$ (que representavam o grupo dos oligarcas que foram alijados do poder após 1930), Erasto Gaertner ${ }^{17}$, Francisco de Paula Soares Neto ${ }^{18}$, Otávio da Silveira ${ }^{19}$, o intelectual David Carneiro e o engenheiro Othon Mader ${ }^{20}$ (um "camarguista ${ }^{21}$ " que rompeu com o interventor Manoel Ribas em 1937).

No início de março de 1945, a Frente Única do Paraná é lançada oficialmente por meio de um manifesto ${ }^{22}$, no qual dava início a uma campanha sistemática à candidatura do Brigadeiro Eduardo Gomes, amplamente divulgada pelo jornal Gazeta do Povo. A Frente Única conseguiu rapidamente angariar inúmeros adeptos, como Bento Munhoz da Rocha Neto (filho de Caetano Munhoz da Rocha ${ }^{23}$ ) e o jornalista Caio Machado (que teve o seu jornal O Dia estatizado por Manoel Ribas), entre inúmeros outros políticos, profissionais liberais, intelectuais e estudantes.

Além da campanha eleitoral em favor do Brigadeiro Eduardo Gomes, a partir de abril de 1945 a Frente Única do Paraná também passou a defender

\footnotetext{
${ }^{15}$ Laerte Munhoz nasceu em Curitiba em 1900, era filho do coronel Alcides Munhoz. Foi jornalista, escritor, bacharel em Direito pela Universidade do Paraná e promotor público em Curitiba desde 1928; presidente do Instituto da Ordem dos Advogados do Paraná e fazia parte do Centro de Letras do Paraná. In: OLIVEIRA, op. cit., p. 21-25.

${ }^{16}$ Arthur Ferreira dos Santos nasceu em Curitiba em 1894. Bacharel em Direito por São Paulo, foi Oficial de Gabinete da primeira gestão de Affonso Camargo e na segunda foi Chefe de Polícia, e promotor público em Curitiba. Foi presidente do Instituto da Ordem dos Advogados do Paraná. In: OLIVEIRA, op. cit., p. 21-25.

${ }^{17}$ Erasto Gaertner nasceu em Curitiba em 1900; era médico pela Universidade do Rio de Janeiro e professor da Universidade do Paraná. In: OLIVEIRA, op. cit,, p. 21-25.

${ }^{18}$ Francisco de Paula Soares Neto nasceu no Rio Grande do Sul em 1901, formou-se médico pela Faculdade de Porto Alegre e foi professor da Faculdade de Medicina do Paraná. Foi presidente da Federação Paranaense de Desportos. Capitão-Médico do Exército e participante ativo da Revolução de 1930. In: OLIVEIRA, op. cit., p. 21-25.

${ }_{19}$ Otávio da Silveira nasceu no Rio Grande do Sul em 1895, formou-se médico pela Faculdade de Porto Alegre e era professor da Universidade do Paraná. Foi Diretor Geral do Ensino e da Saúde Pública e ativo membro do Diretório Central da Aliança Nacional Libertadora (ANL). In: OLIVEIRA, op. cit,, p. 21-25.

${ }^{20}$ Othon Mäder iniciou sua carreira de funcionário público como Delegado de Terras da Região Oeste (1920-1924). Em 1926 torna-se agrimensor de terras, no Departamento de Terras e Colonização e se torna Delegado de Terras no Sudoeste. Exerceu ainda outras funções e cargos: prefeito municipal em Foz do Iguaçu (1932) e Ponta Grossa (1936); entre 1934-36 foi Secretario de Estado da Agricultura; fundador da Associação dos Funcionários Públicos, a dos Engenheiros e a das Seguradoras. In: CODATO, Evandir. "Personalismo político nos anos cinqüenta". In: Revista de História Regional. Ponta Grossa, UEPG, 2002, v. 7, n. 1, p. 12-13.

${ }^{21}$ Os "camarguistas" eram os políticos que pertenceram aos governos anteriores a 1930. Eram chamados de "camarguistas" em alusão ao último presidente do Paraná da República Velha, Afonso Alves de Camargo.

${ }^{22}$ Cf. Ao povo paranaense. In: Gazeta do Povo, 10 mar. 1945, p. 3.

${ }^{23}$ Durante a República Velha, Caetano Munhoz da Rocha presidiu o Paraná durante dois mandatos consecutivos: 1920-1924 e 1924-1928.
} 
sistematicamente a volta do Território do Iguaçu ${ }^{24}$ à jurisdição do Paraná. No final de maio de 1945, a Frente Única integrou-se à UDN, dando origem ao partido no estado ${ }^{25}$.

No entanto, como era esperado, não tardou para que houvesse as primeiras cisões no seio dessa grande coalizão oposicionista. Um dos primeiros grupos a romper com a UDN foi a Esquerda Democrática, em agosto de 1945. Formada por políticos e intelectuais socialistas e antigetulistas, a Esquerda Democrática daria origem ao Partido Socialista Brasileiro (PSB), no início de 1946.

Posteriormente, as dissidências udenistas também deram origem a outros pequenos partidos (todos partidos de menor representatividade em nível nacional e mais ou menos fortes em determinados estados da federação), como o Partido Libertador (PL $\left.{ }^{26}\right)$, o Partido Republicano Progressista ${ }^{27}-$ que em junho de 1946 daria origem ao Partido Social Progressista (PSP ${ }^{28}$ ) - e o Partido Republicano $\left(\mathrm{PR}^{29}\right)$, organizado em 1946. Desses pequenos partidos

\footnotetext{
${ }^{24} \mathrm{O}$ Território Federal do Iguaçu submetia-se diretamente ao governo federal. Foi criado pelo Decreto Lei no 5.812, de 13 de setembro de 1943, e abrangia a região dos municípios paranaenses de Foz do Iguaçu, Iguaçu e Clevelândia, além da região oeste de Santa Catarina. Abrangendo regiões de fronteiras internacionais, o Território do Iguaçu foi criado sob a justificativa de envolver problemas de integridade e segurança nacional e de buscar-se a sua integração ao território nacional.

${ }^{25}$ Cf. A reunião da comissão central da Frente Única do Paraná. In: Gazeta do Povo, 31 maio 1945, p. 5.

${ }^{26}$ Classificado como um partido conservador na sua orientação política, o Partido Libertador (PL) "possuía suas bases no Rio Grande do Sul, na Bahia e em outros poucos estados" e seu principal expoente era o sul-rio-grandense Raul Pilla. Cf. FLEISCHER, David V. Dimensões do recrutamento partidário. In: FLEISCHER, David V. (Org.). Os partidos políticos no Brasil. Brasília: UnB, 1981, v. 1, p. 61.

${ }^{27}$ O Partido Republicano Progressista, registrado em novembro de 1945, foi formado pelo ex-interventor de São Paulo Adhemar de Barros, em fusão com o grupo de João Café Filho, do Rio Grande do Norte. Como Adhemar de Barros era visto com extrema desconfiança dentro da UDN por ser um ex-aliado de Getúlio, foi colocado à margem dentro do partido pelas lideranças udenistas de São Paulo. Ambicioso politicamente, Adhemar optou em criar o seu próprio partido, que teve um fraco desempenho nas eleições de 1945, elegendo apenas dois deputados (Café Filho, pelo Rio Grande do Norte, e Campos Vergal, por São Paulo). Cf. SAMPAIO, Regina. O Partido Social Progressista em São Paulo. In: FLEISCHER, op. cit.

28 "Em junho de 1946, o Partido Republicano Progressista fundiu-se com outros dois pequenos partidos de origem paulista (o Partido Popular Sindicalista e o Partido Agrário Nacional), dando origem ao Partido Social Progressista (PSP)". In: SAMPAIO, op. cit., p. 176. Foi pela sigla pessepista que Adhemar de Barros elegeu-se, em 1947, governador do estado de São Paulo. Com suas bases políticas ancoradas em São Paulo, o PSP foi um dos mais fortes partidos nesse estado. Entretanto, "fora de São Paulo a sigla pessepista era freqüentemente utilizada por políticos a procura de legenda para enfrentar os partidos dominantes (UDN, PSD e às vezes o PTB)". In: FLEISCHER, op. cit., p. 55. Em âmbito nacional, o partido disputou com o PR e, posteriormente, com o Partido Democrata Cristão (PDC) o posto de quarto maior partido representado na Câmara dos Deputados.

${ }^{29}$ Também classificado como um partido conservador, o Partido Republicano (PR), por sua vez, tem as suas raízes nos antigos PRs da República Velha e aglutinava os remanescentes das antigas oligarquias estaduais do pré-1930. Em nível nacional, seu líder máximo era o ex-presidente Arthur Bernardes, cuja morte, em 1955, marcou o início do declínio do partido. Cf. FLEISCHER, op. ct,, p. 60-61.
} 
citados, apenas o PR lograria notoriedade política no Paraná, alcançando o posto de quarto principal partido do estado durante a década de 1950.

Com sua gênese relacionada aos movimentos políticos da Igreja Católica no início dos anos 1930, o Partido Democrata Cristão (PDC) teve uma origem distinta dos demais partidos do período, uma vez que não era uma "criatura" de Vargas. Com as suas principais bases políticas ancoradas nos “estados de São Paulo, Paraná e Rio de Janeiro ${ }^{30 ", ~ o ~ P D C ~ c r e s c e u ~ s i g n i f i c a t i-~}$ vamente, em âmbito nacional, a partir do final da década de 1950 - inclusive elegendo um presidente da República - Jânio Quadros, nas eleições de 1960.

Conforme Luiz Werneck Vianna, após a Segunda Guerra Mundial o PDC emergiu em países católicos europeus e latino-americanos (como na Itália e no Chile) como um partido reformista, defendendo um "capitalismo social" - de acordo com a Rerum Novarum de 1891 - que se tornou atraente para setores da classe média, pequenos proprietários rurais e urbanos, camponeses e operários ${ }^{31}$. Entretanto, no Brasil, o PDC teve uma configuração atípica:

Em confronto com seus similares europeus e latino-americanos, cabe bem a designação de atípica à sua versão brasileira. Seu discurso não se pautou pelo reformismo e, ademais, não se empenhou como um projeto modernizante, tendo cumprido um papel social praticamente inócuo. Ressalvando o curto interregno dos anos 1960, quando alguns líderes tentaram aproximá-lo da doutrina social da Igreja, constitui-se numa legenda a mais, posta a serviço de políticos profissionais sem compromissos programáticos. Quando muito, veio a representar o ritualismo moralizante de certos círculos das camadas médias de alguns centros urbanos de São Paulo e Paraná32. [grifos meus].

Em suma, para Luiz Werneck Vianna o PDC brasileiro foi um partido conservador e geralmente contrário à modernização $0^{33}$, que não contou com o apoio institucional da Igreja e nem dos trabalhadores do campo - apropriados pelo PSD - e dos centros urbanos - que votavam no PTB -, constituindo-se, assim, em um partido das camadas médias e das elites urbanas dos estados industrializados. Assim, "apesar da sua fraseologia 'democrata-cristã', o

\footnotetext{
${ }^{30}$ FLEISCHER, op. cit., p. 58.

${ }^{31}$ Cf. VIANNA, Luiz Werneck. O sistema partidário e o Partido Democrata Cristão. In: FLEISCHER, David V. (Org.). op. cit.

${ }^{32}$ Ibidem.

${ }^{33}$ No seu primeiro programa, o PDC “[...] ao invés de estimular o intervencionismo econômico do Estado - o que, aliás, condiz com o espírito das encíclicas sociais - inclinou-se por um tipo de liberalismo que se identificava melhor com os interesses dos setores agrários adversos à industrialização". Cf. VIANNA, op. cit., 1981, p. 157-158.
} 
PDC se desfez da sua identidade, confundindo-se com a UDN ${ }^{34 "}$ - uma espécie de "UDN católica", parafraseando Gláucio Soares.

No entanto, no final dos anos 1950 e início dos anos 1960, o PDC passou a defender um reformismo moderado, apresentando-se como uma alternativa frente ao conservadorismo da UDN e do PSD e do reformismo-nacionalista do PTB e do PCB. Desse modo, o PDC se consolidou como o quarto principal partido brasileiro em 1962, uma vez que passou a atrair não somente o voto das elites e dos setores médios urbanos, mas também dos trabalhadores urbanos e rurais ${ }^{35}$.

Outros dois partidos significativos no período pluripartidário de 19451965 - e cujas origens não remetem à oposição ou ao apoio a Vargas - foram o Partido de Representação Popular (PRP) e o PCB. O PRP era liderado por Plínio Salgado e defendia a mesma bandeira da Ação Integralista Brasileira (AIB) na década de 1930. Entretanto, "fora do Rio Grande do Sul e do Paraná, o PRP dificilmente operava com legenda própria e sempre em coligação com outros partidos conservadores ${ }^{36 "}$.

Por sua vez, o PCB, de origens bem mais antigas aos demais partidos do período, em 1945, sob a liderança de Luís Carlos Prestes e na legalidade, emergia no cenário político-partidário brasileiro como um partido de massas. Conforme José Antônio Segatto ${ }^{37}$, o PCB, desde 1943, passou a adotar uma política de união nacional ("dentro da lei e da ordem, assentada num regime republicano, progressista e popular"), que o tornou uma agremiação influente na vida política nacional ${ }^{38}$ até 1947 , quando foi colocado novamente na ilegalidade - e, entre 1947-1954, viveu uma fase de radicalização política.

No Paraná, o PCB, cuja existência data desde a década de 1920, também aproveitou a conjuntura da redemocratização para se reorganizar no estado. Assim, em julho de 1945, foram reorganizados o comitê municipal de Curitiba e, em novembro de 1945, o Diretório Estadual do partido ${ }^{39}$.

\footnotetext{
${ }^{34}$ Cf. VIANNA, op. cit., 1981, p. 170-171.

${ }^{35}$ Ibidem.

${ }^{36}$ FLEISCHER, op. cit., p. 58.

${ }^{37}$ Cf. SEGATTO, José Antonio. PCB: a questão nacional e a democracia. In: FERREIRA; DELGADO, op. cit., p. 220-224.

${ }^{38}$ Com a política de união nacional, o PCB havia tornado-se mais "popular" e menos "operário" e as preocupações com os problemas da "nação" predominavam sobre os da "classe", orientando-o, dessa forma, não mais para o proletariado, mas para os patriotas e democratas, conquistando, assim, inclusive a simpatia de setores das camadas médias. In: SEGATTO, op. cit.

${ }^{39}$ Cf. CODATO, Adriano; KIELLER, Marcio (Orgs.). Velhos vermelhos: história e memória dos dirigentes comunistas no Paraná. Curitiba: UFPR, 2008, p. 35.
} 
Já do lado das forças getulistas de continuísmo ocorreu um processo de formação de duas correntes distintas: o PSD e o PTB, "que trariam em suas estruturas e bases organizativas resquícios do Estado Novo ${ }^{40 "}$. O PSD aglutinava os interventores federais, os integrantes da máquina administrativa dos governos federal e estaduais, além de segmentos das oligarquias estaduais, da burguesia e das classes médias urbanas. Dessa forma, o PSD nasceu com uma sólida estrutura organizacional e uma rede clientelista em todos os estados da federação, o que permitiu ao partido lograr significativos êxitos eleitorais ${ }^{41}$.

No Paraná, o PSD foi articulado pelo interventor Manoel Ribas e por integrantes dos altos escalões da máquina administrativa estadual, como o Major Fernando Flores ${ }^{42}$, Roberto Glaser ${ }^{43}$, Angelo Lopes ${ }^{44}$, João Teófilo Gomy Júnior $^{45}$, Lauro Sodré Lopes ${ }^{46}$, e os irmãos Flávio Guimarães ${ }^{47}$, Alô Guimarães ${ }^{48}$ e Acyr Guimarães ${ }^{49}$ - filhos do general Teodorico Gonçalves Guimarães, pertencentes a uma tradicional família do Paraná -, entre outros.

Considerado um partido clientelista, com forte penetração no meio rural, e intimamente ligado à burocracia federal, o PSD é classificado como um partido conservador que "representava os interesses das oligarquias agrícolas e do grande capital financeiro”. Em outras palavras, o PSD excluía,

\footnotetext{
${ }^{40}$ DELGADO, Lucília de Almeida Neves. PTB: do getulismo ao reformismo (1945-1964). São Paulo: Marco Zero, 1989, p. 27-28.

${ }^{41}$ DELGADO, op. cit., 2003, p. 138-139. Mais detalhes sobre o PSD, ver: HIPPOLITO, Lucia. De raposas e reformistas: o PSD e a experiência democrática brasileira (1945-1964). Rio de Janeiro: Paz e Terra, 1985.

${ }^{42}$ O major gaúcho Fernando Flores foi trazido ao Paraná em 1940 por Manoel Ribas, que o nomeou chefe de polícia e, posteriormente, secretário do Interior e Justiça. In: OLIVEIRA, op. cit,, p. 26.

${ }^{43}$ Roberto Glaser nasceu em Canguçu (RS) em 1878. Aos oito anos de idade, mudou-se para Curitiba. Lutou na Revolução Federalista ao lado dos maragatos. Dedicava-se ao jornalismo e atuava na administração de Manoel Ribas. In: NICOLAS, Maria. O Paraná no Senado. Curitiba: Imprensa Oficial, s.d., p. 32.

${ }^{44} \mathrm{O}$ "camarguista" Ângelo Lopes era engenheiro, sendo nomeado por Manoel Ribas seu secretário de Viação, de Fazenda e prefeito de Curitiba

${ }^{45}$ João Teófilo Gomy Júnior era advogado, foi o líder da bancada do antigo PSD na Assembleia Constituinte Estadual de 1935.

${ }^{46}$ Lauro Sodré Lopes era advogado, sendo nomeado por Manoel Ribas promotor público da capital e, posteriormente, chefe de polícia do Estado. In: NICOLAS, Maria. O Paraná na Câmara dos Deputados. Curitiba: Imprensa Oficial, 1977, p. 123.

${ }^{47}$ Flávio Guimarães era advogado e atuava na administração de Manoel Ribas. In: NICOLAS, op. cit., s.d. p.31.

${ }^{48}$ Alô Guimarães era médico e foi nomeado por Manoel Ribas prefeito de Curitiba em 1945. In: NICOLAS, op. cit., s.d. p.35.

${ }^{49}$ Acyr Guimarães era jornalista e proprietário do jornal Gazeta do Povo. In: NICOLAS, op. cit., 1977, p. 101-103.
} 
na prática, os segmentos que eram identificados como as bases fundamentais do novo regime: os trabalhadores.

Portanto, a definição do formato do PSD praticamente estabeleceu os contornos do outro partido "situacionista": o PTB, que ancorou as suas bases a partir da estrutura do Ministério do Trabalho, utilizando-se das lideranças sindicais e dos organismos previdenciários ${ }^{50}$. Inspirado no modelo do Partido Trabalhista Inglês, o PTB não foi uma "invenção de última hora"; pelo contrário, ele surgiu como a coroação organizacional de um longo e cuidadoso esforço de construção de uma ideologia trabalhista no Brasil, que mobilizou muitos recursos humanos, técnicos e financeiros, particularmente no próprio Ministério do Trabalho, desde o ano de 1942, quando Alexandre Marcondes Filho ocupou aquela pasta ${ }^{51}$.

Elegendo os sindicatos como o seu principal local de atuação, o objetivo do PTB era atrair e mobilizar as camadas populares, principalmente nos grandes centros urbanos, para a órbita do partido, apresentando-se como a agremiação partidária que levaria os trabalhadores a alcançar os seus direitos.

No Paraná, o PTB teve sua origem diretamente relacionada ao sindicalismo oficial, pois o partido nasceu da União dos Trabalhadores do Paraná (UTP), uma intersindical que aglutinava diversas federações e sindicatos de todo o estado. A UTP foi arquitetada pelo interventor Manoel Ribas (provavelmente seguindo orientações de Getúlio Vargas e Alexandre Marcondes Filho) e por políticos ligados à interventoria do estado, como o Major Fernando Flores e o advogado trabalhista Milton Viana, que articularam com os líderes sindicais estadonovistas a criação da entidade. Entre os principais líderes da UTP estavam os sindicalistas Lúcio de Freitas ${ }^{52}$ (presidente), Maximino Zanon ${ }^{53}$, João Tavares Santana ${ }^{54}$, Alfredo Santana Ribeiro ${ }^{55}$ e Bernardino Fialho Sobrinho ${ }^{56}$.

\footnotetext{
${ }^{50}$ GOMES, Angela Maria de Castro. A invenção do trabalhismo. 3. ed. Rio de Janeiro: FGV, 2005, p. 283.

${ }^{51}$ Cf. GOMES, Angela de Castro. Partido Trabalhista Brasileiro (1945-1965): getulismo, trabalhismo, nacionalismo e reformas de base. In: FERREIRA, Jorge: REIS, Daniel Aarão (Orgs.). Nacionalismo e reformismo radical (1945-1964). Rio de Janeiro: Civilização Brasileira, 2007, v. 2, p. 57-58.

${ }^{52}$ Atuava nas sociedades beneficentes operárias.

${ }^{53}$ Ex-alfaiate e ex-desportista, também atuava nas sociedades beneficentes operárias.

${ }^{54}$ João Tavares Santana era líder ferroviário.

${ }^{55}$ Alfredo Santana Ribeiro era funcionário público federal, presidente da Federação das Sociedades Beneficentes Operárias e presidente da Sociedade Beneficente Garibaldi.

${ }^{56}$ Bernardino Fialho Sobrinho era presidente do Sindicato dos Empregados nas Indústrias de Moagem de Antonina, Morretes e Paranaguá.
} 
Durante o primeiro semestre de 1945, os dirigentes sindicais da UTP, juntamente com Milton Viana, Rubens de Mello Braga ${ }^{57}$ e o jornalista Jorge Mathias Jr., entre outros, visitaram inúmeras cidades do interior do estado com o intuito de angariar adesões e fundar filiais da entidade nestas localidades. No entanto, o objetivo era mais amplo: criar condições mínimas de estruturação do PTB no estado por meio do sindicalismo estadonovista.

O PTB no Paraná foi oficialmente fundado no dia 8 de julho de 1945, após uma grande convenção realizada na Sociedade Duque de Caxias, em Curitiba, em que a UTP se transformou no partido. A sessão de fundação do PTB no Paraná contou com a presença do sindicalista Luís Augusto França (então presidente nacional do partido) do interventor Manoel Ribas, de políticos pessedistas e de diversos líderes sindicais de todo o estado. Nessa oportunidade, ficou definida a primeira Comissão Executiva do PTB no Paraná, que seria presidida por Maximino Zanon.

Também merece ser ressaltado um aspecto importante: na Convenção que fundou o PTB no Paraná, os petebistas paranaenses e o presidente provisório nacional do partido, Luís Augusto França, aproveitaram a oportunidade para hipotecar total apoio à candidatura do General Eurico Gaspar Dutra, pelo PSD.

Segundo Maria Celina D’Araújo, o apoio de Luís Augusto França à candidatura Dutra representou o início do seu "curto reinado" à frente do partido, pois tal posição "não se coadunava com a orientação queremista do partido, nem com a dos que viam no general o responsável pelos constrangimentos impostos à continuidade de Vargas no poder ${ }^{58 "}$.

Após a I Convenção Nacional do PTB, realizada no final de agosto de 1945, a ala antidutrista, liderada por Paulo Baeta Neves e José de Segadas Viana, consolidou-se na Comissão Executiva Nacional, o que poderia trazer desdobramentos internos no PTB do Paraná, uma vez que a maior fração do partido era, desde o momento da sua fundação, amplamente favorável à candidatura do General Dutra.

Para evitar uma crise com o Diretório Nacional, Maximino Zanon procurou imprimir à seção estadual do partido às orientações de Baeta Neves e Segadas Viana - que eram antidutristas e queremistas ${ }^{59}$. A partir de então, a

\footnotetext{
${ }^{57}$ Rubens de Mello Braga era comerciante e agricultor, organizador de vários sindicatos e um dos líderes da greve dos leiteiros em 1935.

${ }^{58}$ D’ARAUJO, Maria Celina. Sindicatos, carisma \& poder: o PTB de 1945-1965. Rio de Janeiro: FGV, 1996, p. 30-31.

${ }^{59}$ Diário da Tarde, 22 set. 1945, p. 1 (edição das 13h.).
} 
maior fração dos petebistas paranaenses tomaram uma posição equidistante em relação à sucessão presidencial: por um lado, não defendiam mais abertamente a candidatura do Gen. Dutra - embora ainda apoiassem o general de forma velada -; por outro, também não aderiram ao movimento queremista, que em setembro já defendia a tese da "Constituinte com Getúlio".

Em Curitiba, os queremistas organizaram um grande comício "Pró-Constituinte com Vargas" para o dia 26 de setembro, na Praça Osório ${ }^{60}$. Aliás, um dos principais líderes queremistas era o jornalista Roberto Barrozo, do Diário da Tarde, que, por meio das suas colunas diárias, trocava farpas com Acyr Guimarães, também colunista e diretor da Gazeta do Povo, que era partidário do PSD e apoiador da candidatura Dutra.

Por sua vez, o interventor Manoel Ribas, embora fosse acusado de queremista, mostrava-se inclinado a apoiar Dutra, inclusive tendo consentido com a medida do Major Fernando Flores de proibir os comícios não partidários no estado em outubro, cujo objetivo era notoriamente atingir o movimento queremista, em franca ascensão no Paraná.

No entanto, Vargas foi deposto no dia 29 de outubro por um golpe militar encabeçado por Dutra e Góes Monteiro. Provisoriamente, a presidência da República foi ocupada pelo presidente do Supremo Tribunal Federal José Linhares, que adiou as eleições dos executivos estaduais.

Com a queda de Vargas, Manoel Ribas ${ }^{61}$ também caiu no início de novembro, passando o cargo de interventor do estado ao desembargador Clotário de Macedo Portugal, cuja principal missão era garantir as eleições de dezembro.

\section{As eleições de dezembro de 1945 no Paraná}

Em meados de novembro de 1945, a vitória do Brigadeiro Eduardo Gomes já era dada como certa, sobretudo porque Dutra não gozava de popularidade junto aos setores populares por estar envolvido na deposição de Vargas, que, ressentido, recusava-se a apoiar o general ${ }^{62}$. Portanto, a aliança e o apoio do PTB tornaram-se fundamentais para a vitória do Gen. Dutra. Porém, os trabalhistas encontravam-se divididos em três tendências, conforme aponta Lucília de Almeida Neves Delgado63:

\footnotetext{
${ }^{60} \mathrm{Cf}$. Diário da Tarde, 26 set. 1945 (edição das 16h.).

${ }^{61}$ Após a sua deposição, Manoel Ribas assumiu a presidência do PSD no Paraná em novembro de 1945, ocupando o cargo até a sua morte, em janeiro de 1946.

${ }^{62}$ FERREIRA, op. cit., p. 40.

${ }^{63}$ DELGADO, op. cit., 1989, p. 63.
} 
a) A que defendia a abstenção, representada por Baeta Neves e Segadas Viana, que controlavam a Comissão Executiva do partido;

b) A que articulava o apoio a Dutra, cujos principais mentores eram Hugo Borghi, Luiz Augusto França, José Junqueira e Nelson Fernandes;

c) A que propugnava o lançamento de um candidato próprio do PTB. Inicialmente esta posição teria sido recomendada pelo próprio Vargas, que, inclusive, chegou a sugerir, como possíveis alternativas de candidatura, os nomes de João Neves da Fontoura e Osvaldo Aranha.

Ainda conforme a autora ${ }^{64}$, a definição acerca da posição do PTB foi decidida em uma reunião do Diretório Nacional do partido, que, por 17 votos a 13, optou em não lançar nenhum candidato e nem apoiar nenhum outro partido, permanecendo em uma posição de abstenção. No entanto, o grupo dutrista, liderado pelo empresário paulista e líder queremista Hugo Borghi, decidiu não acatar a decisão do Diretório do partido e passou a apoiar o Gen. Dutra. Por sua vez, o PTB paranaense, que desde a sua gênese fora dutrista, também passou por cima da decisão do Diretório Nacional e hipotecou amplo apoio à candidatura Dutra no Paraná65.

Em visível desvantagem eleitoral, o Gen. Dutra conseguiu reverter sua situação nas últimas semanas antes do pleito, sobretudo em virtude do apoio público de Vargas, que se concretizou por meio de um acordo de última hora, conforme relata Maria Celina D’Araújo:

[...] formalizado em 22 de novembro, o acordo Dutra-PTB estabelecia que o Ministério do Trabalho seria entregue ao PTB, que as pastas civis seriam distribuídas proporcionalmente entre os partidos que apoiassem o candidato, que as interventorias seriam distribuídas pelo mesmo critério proporcional e, finalmente, que Dutra apoiaria o programa do PTB e reconheceria e aperfeiçoaria as atuais leis trabalhistas e de amparo social ${ }^{66}$.

Após a aliança Dutra-PTB ter sido selada, Vargas divulgou, no dia 25 de novembro de 1945, um manifesto ao eleitorado brasileiro no qual os aconselhava a votar no general. Tal manifesto foi, sem dúvida, decisivo para a vitória de Dutra, que obteve 55\% dos votos contra 35\% do Brigadeiro Eduardo Gomes e $10 \%$ do comunista Yedo Fiúza ${ }^{67}$. No Paraná, apoiado pelo PSD e pelo PTB, Dutra venceu com uma ampla margem de votos:

\footnotetext{
${ }^{64}$ Ibidem.

${ }^{65}$ Gazeta do Povo, 18 nov. 1945, p. 8.

${ }^{66}$ D’ARAÚJO, op. cit., p. 35.

${ }^{67}$ FAUSTO, Boris. História concisa do Brasil. 2. ed. São Paulo: EDUSP, 2006, p. 220.
} 
Tabela 1 - Resultado das eleições para a Presidência da República no Paraná em 1945

\begin{tabular}{c|c}
\hline Candidato & Número de votos \\
\hline Eurico Gaspar Dutra (PSD) & $70,1 \%(131.690)$ \\
\hline Eduardo Gomes (UDN) & $26,1 \%(48.912)$ \\
\hline Yedo Fiúza (PCB) & $3,5 \%(6.515)$ \\
\hline Outros & $0,3 \%(618)$ \\
\hline
\end{tabular}

Fonte: IPARDES. Resultados eleitorais: Paraná (1945-1982). Curitiba: IPARDES, 1989, p. 9.

Nas eleições para o Senado, a vitória ficou com os dois candidatos pessedistas, Flávio Guimarães e Roberto Glaser, que obtiveram uma ampla votação, superando, inclusive, as candidaturas de Getúlio Vargas ${ }^{68}$ (PTB) e de Luís Carlos Prestes (PCB) ${ }^{69}$. Para a Câmara dos Deputados, o PSD também se sagrou amplamente vitorioso, elegendo seis dos nove deputados federais do Paraná $^{70}$, ao passo que a UDN conquistou duas cadeiras ${ }^{71}$ e o PTB elegeu somente um deputado: Getúlio Vargas ${ }^{72}$. Portanto, as eleições de 1945 no Paraná demonstram algumas tendências já observadas em nível nacional, como a força da máquina partidária do PSD, o grande vitorioso dessas eleições, que contava com uma sólida estrutura administrativa e clientelista no interior do estado.

\footnotetext{
${ }^{68}$ A Lei Agamenon, de 28 de maio de 1945, permitia a candidatura múltipla, podendo o candidato concorrer simultaneamente para presidente, senador ou deputado federal num mesmo ou mais estados. Getúlio Vargas, por exemplo, concorreu a deputado federal em sete estados e a senador em três estados.

${ }^{69}$ Flávio Guimarães (PSD) obteve 76.821 votos; Roberto Glasser (PSD), 70.015; Getúlio Vargas (PTB), 57.756; José de Macedo (UDN), 44.962; José da Rocha Loures (UDN): 38.022; Teodorico Martins (PTB), 22.054; Tasso da Silveira (PRP), 8.326; Manoel Barreto de Alencar, 7.740; Luís Carlos Prestes (PCB), 6.870; Otávio da Silveira (PCB), 6.279. Cf. IPARDES, op. cit., p. 107.

${ }^{70} \mathrm{O}$ PSD elegeu os seguintes deputados federais: Major Fernando Flores, José Munhoz de Melo, Lauro Sodré Lopes, João Aguiar, Aramis T. Athayde e João Teófilo Gomy Júnior (Acyr Guimarães, proprietário do jornal Gazeta do Povo, ficou no posto de suplente e foi frequentemente convocado para o parlamento). Cf. IPARDES, op. cit., p. 14 e 110.

${ }^{71}$ A UDN elegeu Bento Munhoz da Rocha Neto (que depois acompanharia a dissidência que fundaria o Partido Republicano no Paraná) e o médico Erasto Gaertner. Cf. IPARDES, op. cit.

${ }^{72}$ Getúlio Vargas foi eleito senador da República pelos estados do Rio Grande do Sul e São Paulo (sendo derrotado no Paraná) e eleito deputado federal por sete estados da federação: Bahia, Minas Gerais, Rio de Janeiro, Distrito Federal, São Paulo, Rio Grande do Sul e Paraná. Como Vargas optou em assumir a senadoria pelo Rio Grande do Sul, quem assumiu a sua vaga de deputado federal pelo Paraná foi o primeiro suplente Rubens de Mello Braga.
} 


\section{A ascensão de Moysés Lupion na política paranaense e as eleições de 1947}

O ano de 1946 foi bastante agitado nos círculos políticos paranaenses. Logo no início do ano (no final de janeiro) ocorreu o falecimento de Manoel Ribas, ex-interventor e presidente do PSD do Paraná, que era o favorito para vencer as eleições para o governo paranaense em 1947. Em seguida, o interventor Clotário Portugal, considerando sua missão encerrada, decidiu exonerar-se do cargo.

Segundo o jornalista Samuel Guimarães da $\operatorname{Costa}^{73}$, o presidente Eurico Dutra decidiu que o novo interventor do Paraná sairia dos quadros do PSD e solicitou ao Diretório Estadual a indicação de quatro nomes, cujos indicados foram: o advogado Antônio Augusto Carvalho Chaves, o médico Alô Guimarães, o advogado e professor da Universidade do Paraná Brasil Pinheiro Machado e o abastado empresário Moysés Lupion de Tróia ${ }^{74}$, que era amigo íntimo do ex-interventor Manoel Ribas.

Jefferson de Oliveira Salles ${ }^{75}$ revela que Manoel Ribas possuía fortes ligações com o Grupo Lupion ${ }^{76}$, inclusive inserindo alguns indivíduos desse conglomerado no aparelho burocrático do Estado. A relação entre Moysés Lupion e Manoel Ribas era tão próxima que o então interventor instalou o PSD do Paraná em uma sala na empresa de Lupion ${ }^{77}$ - local onde o PSD funcionou nos seus primeiros meses de existência.

Após a morte de Manoel Ribas, Lupion passou a ser considerado o seu herdeiro político e ambicionava chegar ao governo do Paraná. Porém, o nome escolhido pelo presidente Dutra para a interventoria do estado foi o de Brasil Pinheiro Machado, que assumiu o governo em 25 de fevereiro de 1946.

De acordo com Samuel Guimarães da Costa, a missão de Pinheiro Machado era pacificar a política paranaense e garantir uma tranquila

\footnotetext{
${ }^{73}$ Cf. COSTA, Samuel Guimarães. História política da Assembléia Legislativa do Paraná. Curitiba: Assembléia Legislativa, 1994, v. 2, p. 363.

74 Moysés Lupion de Tróia nasceu em Jaguariaiva (PR) em 25 de março de 1908. Formou-se em contabilidade pela Escola Álvares Penteado, em São Paulo. De volta ao Paraná, atuou como empresário do setor madeireiro e construiu um império econômico. In: CARNEIRO, David; VARGAS, Túlio. História biográfica da República no Paraná. Curitiba: Banestado, 1994, p. 199-201.

${ }^{75} \mathrm{Cf}$. SALLES, Jefferson de Oliveira. A relação entre o poder estatal e as estratégias de formação de um grupo empresarial paranaense nas décadas de 1940-1950: o caso do Grupo Lupion. In: OLIVEIRA, Ricardo Costa (Org.). A construção do Paraná moderno: políticos e política no governo do Paraná de 1930 a 1980. Curitiba: SETI, 2004, p. 35-142.

${ }^{76} \mathrm{O}$ Grupo Lupion refere-se ao conjunto de empresas, sobretudo do setor madeireiro, que pertenciam à família de Moysés Lupion e seus sócios.
}

${ }^{77}$ Cf. SALLES, op. cit., p. 97-98. 
sucessão governamental, mas não foi isso o que ocorreu. Primeiramente, porque o novo interventor nomeou um secretariado exclusivamente pessedista e pertencente às tradicionais famílias do estado - os chamados "paranaenses históricos" -, o que gerou grandes descontentamentos entre os demais partidos. Soma-se a isso o fato de que o interventor passou a fazer campanha eleitoral em favor de si mesmo, inclusive promovendo festividades e comícios no interior do estado ${ }^{78}$.

Por outro lado, ambicionado chegar ao governo do Paraná, Moysés Lupion utilizou-se da sua fortuna para promover a sua candidatura, comprando jornais - como O Dia ${ }^{79}$, de Curitiba, e Correio do Paraná, de Londrina, além de $49 \%$ da Gazeta do Povo, de Curitiba - e emissoras de rádios, como a Rádio Sociedade Guairacá Ltda., em Curitiba - que controlava seis outras emissoras no interior do Paraná ${ }^{80}$.

As duas pré-candidaturas pessedistas (Pinheiro Machado e Moysés Lupion) à sucessão estadual de 1947 acabaram gerando uma crise política no Paraná e polarizando as posições dentro do PSD e do PTB, uma vez que havia dentro desses partidos uma pequena ala simpática ao interventor e outra forte corrente que defendia a candidatura de Lupion.

Aliás, convém observar que a candidatura do pessedista Moysés Lupion foi lançada pelo PTB paranaense, onde havia um grupo que a defendia enfaticamente e que deu início a uma sistemática campanha de oposição ao interventor Pinheiro Machado por meio de um jornal trabalhista denominado Diário Popular, fundado no dia $1^{\circ}$ de maio de $1946^{81}$. Impresso nas oficinas do jornal lupionista O Dia, o Diário Popular tinha como diretor Raul Viana, como gerente Abilon de Souza Naves ${ }^{82}$ e como secretário o jornalista Jorge

\footnotetext{
${ }^{78}$ COSTA, op. cit., p. 363-364.

${ }^{79} \mathrm{O}$ jornal O Dia foi arrendado junto ao governo paranaense por Lupion no início de 1946. Dirigido por Raul Vaz, amigo e homem de confiança de Lupion, esse jornal tornou-se o órgão oficial do lupionismo. Com grande circulação por todo estado, propagandeou o nome de Lupion por todo o Paraná.

${ }^{80}$ SALLES, op. cit., p. 98.

${ }^{81}$ O período de circulação do Diário Popular não foi longo: de maio de 1946 até fevereiro de 1947. Posteriormente, o jornal voltou a circular também por um período efêmero, entre abril e outubro de 1948.

${ }^{82}$ Abilon de Souza Naves foi a principal liderança trabalhista do Paraná. Contador de formação, atuava como delegado regional do Instituto de Aposentadoria e Pensões dos Comerciários (IAPC) e trabalhava na área comercial do jornal Gazeta do Povo. Em 1946, Souza Naves, que possuía vínculos de amizade com Moysés Lupion, passou a gerenciar o jornal Diário Popular (órgão trabalhista financiado por Lupion) e ascendeu à Comissão Executiva Estadual do PTB do Paraná como vice-presidente. Em 1948, após a morte de Maximino Zanon, Souza Naves passou a presidir provisoriamente o partido, até ser eleito presidente efetivo da Executiva Estadual em outubro de 1949. Após algumas disputas internas dentro do partido, Souza Naves foi gradativamente consolidando-se como a principal liderança trabalhista do Paraná e integrou a Executiva Nacional do partido, onde era um fiel aliado de Getúlio Vargas e João Goulart. Permanecendo
} 
Mathias Jr., todos membros do PTB paranaense e amigos de Lupion.

Por outro lado, havia um grupo de petebistas que eram contrários à "lupionização" do partido, dentre os quais o jornalista Roberto Barrozo, diretor do jornal Diário da Tarde, que, passaria a utilizar as páginas do seu jornal para criticar duramente a Executiva Estadual do PTB e, principalmente, Lupion, de quem se tornaria o mais ferrenho opositor.

Além dos vínculos com Lupion, outro fator que levou a deterioração das relações do PTB com Pinheiro Machado foi a exclusão dos trabalhistas da administração do Estado, assim como não designar a interventoria da capital e de algumas cidades do interior do estado aos petebistas ${ }^{83}$. Diante desse quadro, o PTB, em uma reunião realizada no dia 29 de abril de 1946, decidiu romper com o interventor e lhe fazer oposição ${ }^{84}$.

No entanto, tal decisão catalisou uma grave crise interna, pois um grupo de petebistas não concordava com o rompimento do partido com o interventor e do apoio dado à candidatura de Lupion. Essa fração do PTB alegava que o referido rompimento fora uma decisão somente do presidente Maximino Zanon e de alguns membros da Executiva Estadual, que a tomaram sem consultar os diretórios municipais do interior do estado ${ }^{85}$. No final de maio de 1946, a crise nas hostes petebistas culminou na expulsão de diversos membros ${ }^{86}$, configurando a primeira grande cisão dentro do partido.

Combatido pelo PTB e dentro do seu próprio partido, o PSD, o clima político no Paraná tornou-se insustentável para Pinheiro Machado, que acabou renunciando e sendo substituído pelo Tenente Coronel Mário Gomes da Silva, em outubro de 1946. O novo interventor, que contava com o apoio do $\mathrm{PTB}^{87}$, adotou um discurso de pacificar a política paranaense e garantir a

no comando do PTB paranaense por mais de dez anos, Souza Naves conseguiu reestruturar e fortalecer o partido, que se consolidaria como uma das principais forças políticas do Paraná ao longo da década de 1950. Nas eleições de 1958, Souza Naves elegeu-se senador, porém, faleceu em dezembro de 1959.

${ }^{83}$ Os petebistas queriam as interventorias de Curitiba, Ponta Grossa, Colombo, Araucária, Piraquara, Guarapuava, Irati, Rio Negro, Tibagi, Jaguariaiva, Imbuial, mas só conseguiram as cidades de Teixeira Soares e Cornélio Procópio. In: Diário da Tarde, 13 maio 1946, p. 4.

${ }^{84}$ Cf. Diário Popular, 1ํmaio 1946; Diário da Tarde, 3 maio 1946, p. 1 (edição das 13h.).

${ }^{85}$ Cf. BARROZO, Roberto. "Do navio à canoa". Diário da Tarde, 13 jun. 1946, p. 1.

${ }^{86}$ Foram expulsos vários membros que tiveram importante atuação na fundação do PTB do Paraná. Dentre os expurgados estavam, entre outros, Milton Viana, que teve uma destacada atuação na organização da UTP e do PTB, além dos líderes sindicais Theodorico Ferreira Martins, Alfredo Santana Ribeiro e Sinibaldo Trombini, que, inclusive, concorreram nas eleições de dezembro de 1945 como candidatos do partido.

${ }^{87}$ O interventor Mário Gomes dividiu algumas secretárias para o PTB e a UDN, mas excluiu o PR, que era simpático ao ex-interventor Pinheiro Machado. 
idoneidade das eleições estaduais de janeiro de 1947.

Sobre o novo interventor, o jornalista Samuel Guimarães Costa fez a seguinte observação:

Quanto ao novo interventor Mário Gomes, tratava-se de quase um ilustre desconhecido. Pertencia aos quadros da Intendência do Exército, tendo servido antes na $5^{a}$ Região Militar. Fora chefe de Polícia em Santa Catarina e, na ocasião de sua nomeação, um dos diretores do parque siderúrgico de Volta Redonda. Sem maiores vínculos políticos no Paraná, chamou para a pasta do Interior, Justiça e Segurança o já famoso e então deputado federal Fernando Flores $^{88}$.

O deputado federal Major Fernando Flores - que era bastante conhecido e muito influente nos círculos políticos paranaenses - teve uma atuação destacada na defesa da candidatura de Lupion, sobretudo a partir do momento em que o PSD paranaense encontrou-se novamente dividido entre dois pré-candidatos ao governo do estado: Lupion e o Gen. José Agostinho dos Santos.

A disputa interna nas hostes pessedistas repercutiu amplamente na política paranaense. A ala lupionista do PSD chamou a possível candidatura do Gen. Agostinho dos Santos, apoiado por cerca de dois terços da Comissão Executiva do partido, de "grande golpe ${ }^{89 "}$. Embora minoritários dentro do partido nesse momento, os lupionistas, liderados pelo Major Fernando Flores, utilizaram-se amplamente dos jornais - como a Gazeta do Povo, O Dia e o Diário Popular - para atacar a possível candidatura do Gen. Agostinho dos Santos.

Diante do crescimento da candidatura do Gen. Agostinho dos Santos, que contava com a simpatia da maioria do Diretório pessedista - cujo principal articulador era o ex-interventor Pinheiro Machado -, o presidente do PSD paranaense, Antonio Augusto Carvalho Chaves, lançou um manifesto pedindo a coalizão dos principais partidos do estado em favor do nome de Lupion, inclusive denominando a sua ala de "liberal" e a liderada por Pinheiro Machado de "radical" 90.

Em suma, a estratégia utilizada pelos lupionistas, que nesse momento estavam em minoria dentro do PSD, foi tentar organizar uma grande coalizão interpartidária com o PTB - que possuía um diretório amplamente lupionista -, a UDN e o PRP. Outra estratégia utilizada foi a cooptação dos

\footnotetext{
${ }^{88}$ COSTA, op. cit., p. 364-365.

${ }^{89}$ Cf. Gazeta do Povo, 9 out. 1946; Diário da Tarde, 10 out. 1946.

${ }^{90}$ Cf. Gazeta do Povo, 13 out. 1946, p. 1.
} 
diretórios pessedistas dos municípios do interior do Paraná para que esses apoiassem a candidatura de Lupion na Convenção Estadual pessedista, que seria realizada no início de novembro de 1946.

Neste sentido, o jornalista Samuel Guimarães Costa relata que o interventor Mário Gomes também contribuiu indiretamente para o êxito dessa estratégia, pois foi totalmente omisso ao fato do seu secretário, o Major Fernando Flores, se aproveitar da sua posição política para articular com os diretórios pessedistas do interior e com outros partidos políticos, o que foi fundamental para o fortalecimento da candidatura de Lupion ${ }^{91}$.

Desse modo, em pouco tempo a ala lupionista do PSD conquistou o apoio da UDN e do PRP, que, juntamente com o PTB, acordaram em dividir secretarias e outros cargos públicos entre os partidos coligados. Assim, no final de outubro de 1946 os jornais já noticiavam a coalizão.

No entanto, o jornalista antilupionista Roberto Barrozo, que apoiava a candidatura do Gen. Agostinho dos Santos, criticou duramente a UDN pela coalizão lupionista e pela sua contraditória aliança com o $\mathrm{PTB}^{92}$, que também foi alvo da ira de Barrozo:

O PTB do Paraná está dominado por alguns cidadãos sem cultura, sem projeção sem consciência política. Estão submissos ao Sr. Moysés Lupion de Tróia, do diretório estadual do PSD. [Ele] custeia as principais despesas do partido, sendo assim, o mesmo perdeu sua autonomia. Estão fazendo do partido um rendoso negócio, nem ao menos admitiram a candidatura de ilustre Sr. Ivo Leão, que sempre esteve em defesa dos trabalhadores. Fernando Flores, que tanto perseguiu e cercou de violência a ala sindical do PTB, é hoje o coordenador da candidatura do Sr. M. Lupion. Lançaram o Sr. Maximino Zanon para senador e agora o deixam para apoiar o Dr. Arthur Ferreira dos Santos, da UDN, e inimigo de G. Vargas, condutor do PTB. Estes supostos trabalhistas abriram as portas do Partido, ao assalto por elementos de outros Partidos. Sendo assim, o PTB não tem candidato a governador e nem a senador. Os dirigentes trabalhistas se ligaram ao Sr. Moisés Lupion. Essa atitude de subserviente destes dirigentes é muito depressiva. Tanto que os homens de bem e que se prezam não provam e nem aceitam tais atitudes ${ }^{93}$.

Roberto Barrozo - que teve as suas aspirações de crescimento pessoal dentro do PTB frustradas e, por isso, migrou para o PSP - acusava a Executiva petebista de ter vendido o partido a Lupion e faz referência ao fato dos trabalhistas, em prol da grande coalizão, terem abdicado de lançar

\footnotetext{
${ }^{91}$ COSTA, op. cit., p. 364-365.

${ }_{92}$ Cf. Transigindo com a ditadura. Diário da Tarde, 4 nov. 1946, p. 1.

${ }^{93}$ Cf. BARROZO, Roberto. “Espanando cadeiras”. Diário da Tarde, 4 nov. 1946, p. 1.
} 
a candidatura de Maximino Zanon ao Senado e apoiarem o udenista Arthur Ferreira dos Santos.

No entanto, apesar de todas as contradições inerentes, a grande coalizão entre PSD, PTB, UDN e PRP em favor de Lupion foi ratificada nas respectivas convenções estaduais destes partidos. Na Convenção do PSD, realizada em 7 de novembro de 1946, a ala lupionista - que se auto-denominava "ala liberal” - saiu vencedora graças ao apoio dos diretórios do interior. Assim, os trabalhos de articulação empreendidos pelo Major Fernando Flores foram bem sucedidos.

Por sua vez, a Convenção petebista ocorreu no dia 5 de novembro de 1946. Como já era esperado, o PTB oficializou o seu apoio a Lupion e lançou a lista de candidatos ao Legislativo estadual. Para o Senado, o partido confirmou o apoio ao udenista Arthur Ferreira dos Santos e lançou o nome de Maximino Zanon como o seu suplente.

Oficializado candidato pela coligação PSD-PTB-UDN-PRP, Lupion enfrentaria nas urnas Bento Munhoz da Rocha Neto, do Partido Republicano (PR). Contudo, o jornalista Samuel Guimarães Costa ${ }^{94}$ relata que a candidatura de Lupion era praticamente invencível, pois contava com o apoio oficial dos três principais partidos e dispunha de muitos recursos financeiros. Com o seu nome sendo propagandeado em todo o estado por meio de rádios e jornais de grande circulação (O Dia e a Gazeta do Povo), Lupion dizia-se representar a renovação - uma vez que não pertencia às famílias tradicionais, ao contrário de Bento Munhoz da Rocha Neto ${ }^{95}$.

Utilizando-se de um discurso popular (cujo slogan era "Paraná maior"), Lupion prometeu apoiar as cidades e os interesses do interior do Paraná, enquanto Bento Munhoz da Rocha Neto era representado como um candidato das elites curitibanas ${ }^{96}$. Assim, Lupion viu crescer a sua popularidade e venceu as eleições de 19 de janeiro de 1947 com uma ampla margem de votos:

\footnotetext{
${ }^{94}$ COSTA, op. cit., p. 366.

${ }^{95}$ Filho de Caetano Munhoz da Rocha (que governou o Paraná entre 1920-1928), Bento Munhoz da Rocha Neto e era considerado herdeiro político das velhas oligarquias destronadas após a Revolução de 1930 que retornaram à política no pós-1945 concentrando-se na UDN e, em menor número, no PR.

${ }^{96}$ Cf. MAGALHÃES, Marion Brepohl. Paraná: política e governo. Curitiba: SEED, 2001, p. 56.
} 
Tabela 2 - Resultado das eleições para o governo do Paraná em 1947

\begin{tabular}{c|c|c|c}
\hline Candidato & Partido/Coligação & № de votos & $\%$ \\
\hline Moysés Lupion de Tróia & PSD/PTB/UDN/PRP & 90.251 & $59,1 \%$ \\
\hline Bento Munhoz da Rocha Neto & PR & 44.809 & $29,3 \%$ \\
\hline Brancos & & 11.228 & $7,3 \%$ \\
\hline Nulos & & 6.522 & $4,3 \%$ \\
\hline Total & & 152.810 & $100 \%$ \\
\hline
\end{tabular}

Fonte: IPARDES, op. ct., p. 11.

Para o Senado, o udenista Arthur Ferreira dos Santos (que contava com o apoio do PSD, do PTB e do PRP) derrotou o jornalista Roberto Barrozo $(\mathrm{PSP})^{97}$. No que tange à Assembléia Legislativa do estado, o $\mathrm{PSD}^{98}$ sagrou-se o grande vitorioso, elegendo 16 deputados, enquanto a UDN ${ }^{99}$ elegeu sete, $\mathrm{O}$ $\mathrm{PTB}^{100}$ seis, o PR ${ }^{101}$ quatro, o PRP ${ }^{102}$ dois, o $\mathrm{PSP}^{103}$ um e o $\mathrm{PCB}^{104}$ também um ${ }^{105}$. Dessa forma, Moysés Lupion pôde, inicialmente, governar o Paraná com a maioria absoluta do Legislativo estadual, pois a grande coalizão interpartidária aglutinou $83,7 \%$ dos deputados.

\section{O governo de Moysés Lupion e o fim da grande coalizão interpartidária}

Após as eleições, Mário Gomes passou a interventoria do estado a Antonio Augusto Carvalho Chaves, presidente do PSD paranaense, que

\footnotetext{
${ }^{97}$ Arthur Ferreira dos Santos obteve 73.837 votos, contra 42.990 de Roberto Barrozo. Cf. IPARDES, op. cit., p. 107. Dessa forma, a senatoria paranaense (1947-1950) ficou completa, ficando assim composta: Flávio Guimarães (PSD), Roberto Glaser (PSD) e Arthur Ferreira dos Santos (UDN).

${ }_{98}$ O PSD elegeu João Chede, Oscar Lopes Munhoz, Antonio Lustosa de Oliveira, Avelino Vieira, Edgard Sponholz, Justiniano G. da Silva, Alfredo Pinheiro Júnior, Ernani Benghi, Alcides Pereira Júnior, Guataçara Borba Carneiro, Helio Setti, Anísio Luz, José M. Ribeiro dos Santos, Waldemiro Pedroso, Pedro Firman Neto e Francisco Accioly R. da Costa Filho.

${ }^{99}$ A UDN elegeu Bronislau Ostoja Rogushi, Lineu Madureira Novais, Osvandré Ferreira do Amaral e Silva, Rivadávia Barbosa Vargas, Alvir Riesemberg, José Alves Bacelar e Laertes de Macedo Munhoz.

${ }^{100}$ O PTB elegeu Aldo Silva, Aldo Laval, Antônio dos Santos Filho, Julio Rocha Xavier, José Machuca e José Daru.

${ }^{101}$ O PR elegeu Felizardo Gomes da Costa, Lauro Gentil Portugal Tavares, Francisco Peixoto de Lacerda Werneck e Frederecindo Mares de Souza.

${ }^{102}$ O PRP elegeu Júlio Buskei e Benjamin de Andrade Mourão.

${ }^{103}$ O PSP elegeu Atílio de Almeida Barbosa.

${ }^{104}$ O PCB elegeu José Rodrigues Vieira Neto.

${ }^{105}$ Cf. IPARDES, op. cit., p. 122.
} 
ficou pouco mais de um mês no cargo, até a posse de Moysés Lupion, em março de 1947. De uma maneira geral, o primeiro governo de Lupion (19471951), cujo lema era "construindo um Paraná Maior", priorizou as políticas de colonização nas regiões norte, oeste e sudoeste do estado, investiu em algumas obras de infra-estrutura (sobretudo a abertura de novas estradas) e adotou uma tímida política de modernização/industrialização do estado - contudo, convém ressaltar que durante a década de 1950 o Paraná ainda seria um estado predominantemente agrícola.

Inicialmente, conforme o jornalista Samuel Guimarães Costa ${ }^{106}$, Lupion montou seu secretariado visando a contemplar os partidos que formaram a grande coalizão que o elegeu, porém com as principais secretarias divididas entre o PSD e a UDN. Contudo, durante a Assembléia Constituinte paranaense teve início os primeiros desentendimentos entre o PSD e a UDN. No final de 1947, a crise entre os dois partidos acentuou-se e o iminente rompimento foi oficializado no início de 1948. A partir de então a UDN empreendeu uma ferrenha oposição ao governo Lupion, tornando-se uma implacável e eterna inimiga do governador paranaense.

Internamente, o PSD e o PTB paranaense também estavam em ebulição. Os pessedistas encontravam-se divididos em dois grupos: de um lado, estavam os deputados lupionistas; de outro, os deputados "granadeiros ${ }^{107 "}$ ", que criticavam abertamente o governador. Por sua vez, o PTB do Paraná vivia um período de disputas pelos altos escalões do partido e por dissidências.

Porém, a crise interna do PTB paranaense tenderia a agravar-se ainda mais: em 22 de janeiro de 1948 ocorreu o falecimento do seu presidente Maximino Zanon; em fevereiro de 1948, o PTB do Paraná - dirigido provisoriamente pelo vice-presidente Abilon de Souza Naves - enfrentou uma grande cisma, quando inúmeros trabalhistas - incluindo cinco dos sete deputados estaduais do partido ${ }^{108}$ - migraram para o PSD.

Embora os dissidentes petebistas alegassem desentendimentos com a Executiva do partido, há fortes indícios de que o real motivo para a cisão no PTB tenha sido fomentado pelo governador Lupion e pelo PSD, que cooptou os mencionados deputados estaduais e outros influentes trabalhistas para as hostes pessedistas para compensar a rebeldia dos deputados granadeiros.

\footnotetext{
${ }^{106}$ COSTA, op. cit., p. 368 .

${ }^{107}$ Os quatro deputados floristas conhecidos como "granadeiros" eram Oscar Lopes Munhoz, Pedro Firman Neto, Alfredo Pinheiro Jr. e Francisco Acioli Filho.

${ }^{108}$ Os deputados dissidentes eram Antônio dos Santos Filho, Aldo Laval, Aldo Silva, José Darú e Júlio Buskei (que havido sido eleito pelo PRP, mas migrou para o PTB em 1947).
} 
Em outras palavras, o PSD, que já havia rompido com a UDN, planejou cooptar os deputados trabalhistas, pois assim garantiria a maioria no Legislativo e poderia romper a coligação com o PTB e, dessa forma, governar o Paraná sozinho, como era a vontade de alguns influentes pessedistas.

Após estimular a dissidência dentro do PTB, o governador Lupion e o PSD trataram de colocar os petebistas à margem do governo estadual. A partir de então, as relações entre o PTB paranaense e o governador se deterioraram e, gradativamente, os petebistas passaram a fazer oposição a Lupion, cujo rompimento foi oficializado, em setembro de 1948.

\section{Considerações Finais}

Após o processo de redemocratização de 1945 no Paraná observou-se algumas tendências já constatadas em nível nacional, como a força eleitoral do PSD, partido que nasceu solidamente estruturado e obteve bons resultados eleitorais nas eleições de 1945 e 1947. Ademais, também se verificou que durante a segunda metade da década de 1940 a UDN ocupava a posição de segundo principal partido político no Paraná, ao passo que o PTB estava na terceira posição, uma vez que o partido nasceu fraco e enfrentava inúmeras dificuldades estruturais e financeiras durante os seus primeiros anos de existência.

Durante os primeiros anos de vigência do regime democrático pós-Estado Novo também ocorreu a ascensão política do abastado empresário Moysés Lupion, que se tornou o principal líder do PSD paranaense, elegeu-se governador nas eleições de 1947 e se consolidaria como um dos principais nomes da política paranaense do período em foco, inclusive elegendo-se senador em 1954 e novamente governador em 1955. De uma maneira geral, pode-se concluir que o Paraná esteve polarizado politicamente em dois grupos ao longo do período pluripartidário de 1945-1965: de um lado, estavam os lupionistas, que englobava a maior parte do PSD e uma ala do PTB; de outro, estavam os antilupionistas, que aglutinava, sobretudo, políticos da UDN, do PTB, do PR, do PRP e do PDC.

Artigo recebido para publicação em 30/05/2015

Artigo aprovado para publicação em 04/11/2015 